\title{
Strong Correlation Between Serum Levels of Inflammatory Mediators and Their Distribution in Infarct-Related Coronary Artery
}

\author{
Hon-Kan Yip, MD; Cheuk-Kwan Sun, MD*; \\ Li-Teh Chang, PhD**; Chiung-Jen Wu, MD
}

\begin{abstract}
Background Little is known regarding the correlation between circulating levels of inflammatory mediators and their distribution within the infarct-related coronary artery (ICA).

Methods and Results Atherothrombotic tissue and blood were aspirated by export suction catheter from the ICA in 49 patients with an acute myocardial infarction (AMI) $<6 \mathrm{~h}$ duration who underwent primary percutaneous coronary intervention (PCI). Blood samples were collected before PCI for levels of high-sensitivity (hs) C-reactive protein (CRP), soluble P-selectin (sP-selectin) and white blood cell (WBC) counts. Immunohistochemical staining was performed for localization of CRP within the ICA. Staining intensity was graded for macrophage and extracellular tissue (0: no staining; $1+:<30 \%, 2+: 30 \%$ to $60 \%$, and $3+:>60 \%$ ). The hs-CRP levels were markedly higher in grade $3+$ compared with both grade $2+$ and grade $1+$ of macrophage and extracellular staining of CRP (all $p$ values $<0.0001)$, and in grade $2+$ compared with grade $1+(\mathrm{p}<0.001)$. Additionally, the ICA had a significantly higher sP-selectin level and WBC count compared with the systemic circulation $(\mathrm{p}<0.0001)$. Furthermore, the ICA level of sP-selectin was noticeably higher in patients with a total atherothrombus volume $\geq 0.5 \mathrm{~cm}^{3}$ than in patients with total volume $<0.5 \mathrm{~cm}^{3}(\mathrm{p}<0.0001)$. Moreover, correlation analysis demonstrated that the increase in the ICA level of sP-selectin was significantly related to the increase in the WBC count in the artery $(\mathrm{r}=0.548, \mathrm{p}<0.0001)$. Multiple analysis identified an increased circulating level of hsCRP as the only independent predictor of $\geq 2+$ in macrophage $(p<0.0001)$ and $\geq 2+$ in extracellular $(p<0.0001)$ staining of CRP.

Conclusions Following AMI, the sP-selectin level and WBC count were markedly higher in the ICA than in the circulation. Moreover, the circulating level of hs-CRP was strongly associated with ICA localization of CRP. (Circ J 2006; 70: 838-845)
\end{abstract}

Key Words: Acute myocardial infarction; Immunohistochemical staining; Inflammatory mediators

$\mathbf{T}$ he participation of numerous inflammatory mediators in the inflammatory process involving endothelium and smooth muscle is essential in the development of all stages of atherosclerosis, from initiation, progression, and finally to the evolvement of complications!-6 Pathologic and immunohistochemical staining (IHCS) studies have clearly shown a preponderance of inflammatory cells in ruptured plaques of patients dying from acute coronary syndromes? ? $^{-9}$

An increasing number of studies have reported that Creactive protein (CRP), an index of inflammation, directly participates in the atherosclerotic process ${ }^{2,3,6,10-12}$ Numerous investigations have shown that CRP is one of the most important predictors of newly ruptured plaque and vascular

(Received November 7, 2005; revised manuscript received March 27, 2006; accepted May 2, 2006)

Division of Cardiology, Chang Gung Memorial Hospital, Chang Gung University College of Medicine, *Department of General Surgery, Chang Gung Memorial Hospital, Chang Gung University College of Medicine, Kaohsiung and **Division of Basic Medical Science, Department of Nursing, Meiho Institute of Technology, Pingtung, Taiwan

Mailing address: Chiung-Jen Wu, MD, Division of Cardiology, Department of Internal Medicine, Chang Gung Memorial Hospital, 123, Ta Pei Road, Niao Sung Hsiang, Kaohsiung Hsien, 83301, Taiwan.

E-mail: tang@adm.cgmh.org.tw death in various clinical settings $!^{13-15}$ Recently, an autopsy study has demonstrated that an increased serum level of CRP measured by high-sensitivity assay (hs-CRP) is significantly related to atherothrombi and plaque burden in patients dying suddenly of severe coronary artery disease?

$\mathrm{P}$-selectin is a cell adhesion molecule produced by activated platelets and endothelial cells and is important in modulating the interaction of these cells with neutrophils and monocytes, thereby contributing to thrombus formation! ${ }^{19-19}$ Previous works have indicated that P-selectin mediates the accumulation of leukocytes, which in turn promotes fibril deposition ${ }^{20}$ Others have shown that Pselectin expression on platelets determines platelet aggregate size and stability 21

Recent studies have demonstrated that elevation of the white blood cell (WBC) count during acute myocardial infarction (AMI) is associated with reduced epicardial blood flow and myocardial reperfusion, thromboresistance, and adverse outcomes ${ }^{22,23}$ Accordingly, an association between an elevated WBC count and the infarct-related coronary artery (ICA) thrombus burden has been suggested,22 but to date no direct evidence exists to further support this observation in survivors of AMI.

Therefore, this study tested the hypotheses that circulating levels of hs-CRP correlate with the immunohistochemical localization of CRP in the ICA, and that the soluble (s) 


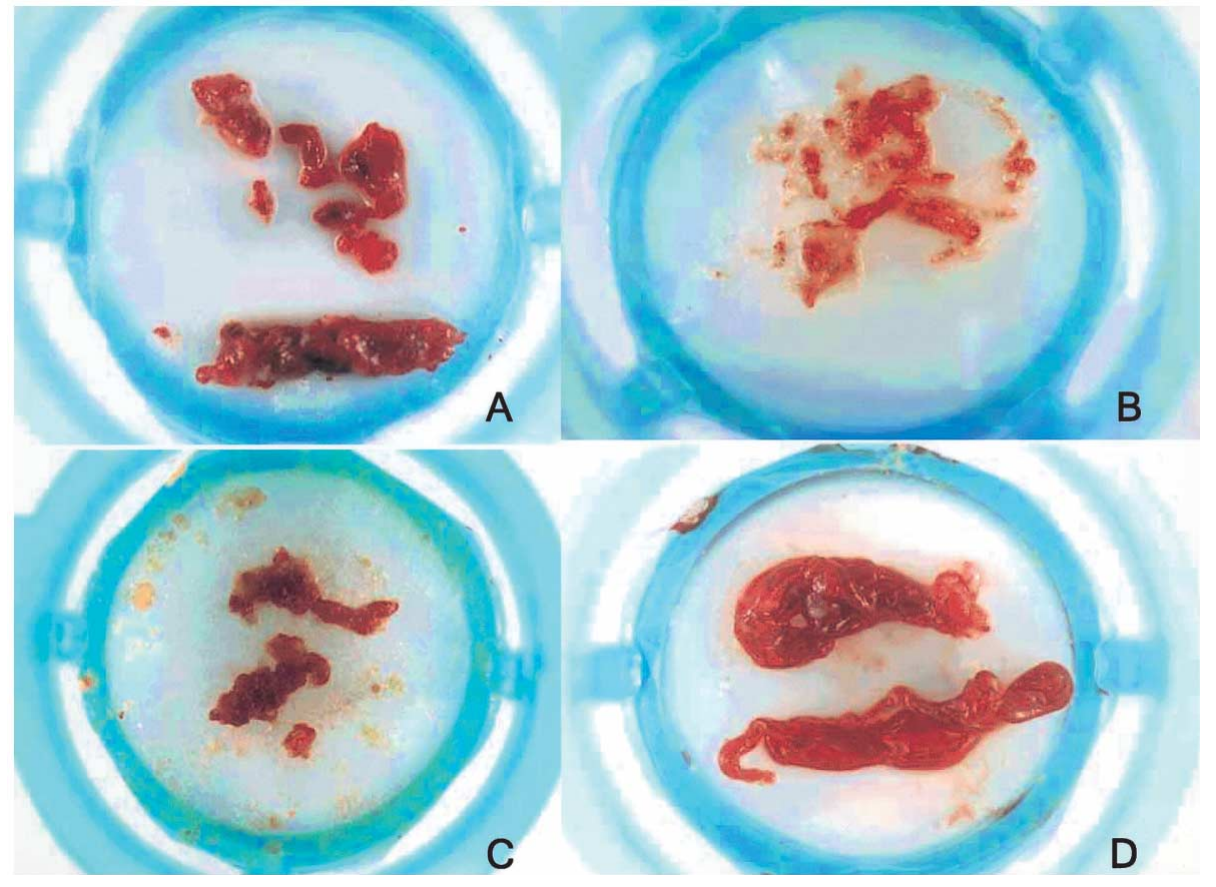

Fig 1. Atherothrombosis aspirated by export suction catheter from 4 cases (A-D). Yellowish cholesterol and debris in the filter $(\mathrm{B}, \mathrm{C})$.
P-selectin level and WBC count are significantly increased in the ICA than in the circulation in patients with AMI of $<6 \mathrm{~h}$ duration undergoing primary percutaneous coronary intervention (PCI).

\section{Methods}

\section{Patient Population and Inclusion Criteria}

All patients with AMI of $<12 \mathrm{~h}$ duration were considered eligible for primary PCI. The PercuSurge GuardWire ${ }^{\mathrm{TM}}$ device (Medtronic AVE) was used as a precaution against distal embolization in patients during primary PCI if the angiographic results complied with the following criteria: (1) the angiographic morphologic features of the ICA showed high-burden thrombus formation as defined in our recent study; ${ }^{24}$ (2) reference lumen diameter (RLD) of the ICA $\geq 3.5 \mathrm{~mm}$; and (3) AMI $<12 \mathrm{~h}$. Exclusion criteria were: (1) RLD of ICA $<3.5 \mathrm{~mm}$; (2) heavily calcified ICA; and (3) very tortuous ICA.

To avoid other variables that could influence the serum levels of hs-CRP and sP-selectin, and the WBC count, we excluded patients with a history of recent surgery or trauma within the preceding 2 months, renal insufficiency (creatinine $>1.5 \mathrm{mg} / \mathrm{dl}$ ), malignancy or liver cirrhosis, febrile disorders, acute or chronic inflammatory disease on study entry or history of recent infection, and those with AMI onset $\geq 6 \mathrm{~h}$. Patients were also excluded if fever (body temperature $>37.5^{\circ} \mathrm{C}$ ) was observed in the emergency room.

Between October 2002 and April 2004, a PercuSurge GuardWire $^{\mathrm{TM}}$ device (Medtronic AVE) was used to prevent distal embolization in 147 consecutive patients presenting with AMI $(<12 \mathrm{~h})$. Of these, 63 patients who upon presentation had experienced the onset of AMI $>6 \mathrm{~h}$ were excluded. Of the remaining 84 patients with AMI $<6 \mathrm{~h}, 35$ were further excluded because of either incomplete occlusion of the ICA or atherothrombus was not aspirated from their ICA during the procedure. Thus, 49 patients who had atherothrombi aspirated from the ICA (Fig 1) comprised the study population.
Forty-five subjects who had experienced angina and undergone their first elective PCI were matched for age, gender, and the existence of hypertension, diabetes mellitus, current smoking habit, as well as hypercholesterolemia, and served as at-risk controls. Informed consent was given by each study subject. The Institutional Review Committee on Human Research approved the study protocol.

\section{Procedure and Protocol}

A transradial approach using a 6Fr arterial sheath has been the design protocol for AMI at Chang Gung Memorial Hospital since 2001. When diagnostic results demonstrated that the ICA met the criteria for PercuSurge device therapy, the $6 \mathrm{Fr}$ arterial sheath was replaced with a $7 \mathrm{Fr}$ arterial sheath, and a 7Fr standard interventional guiding catheter was selectively positioned in the culprit artery. Thrombectomy with an export suction catheter was performed after the distal protection balloon was inflated prior to coronary angioplasty. Blood samples for the ICA levels of hs-CRP and sP-selectin and the WBC count were obtained using the Export Suction Catheter beyond the occluded lesion at the beginning of the procedure. To avoid the possibility of dilution of these inflammatory mediators, $2-3 \mathrm{ml}$ of blood inside the guiding catheter was first removed followed by the collection of 6-8 $\mathrm{ml}$ of blood from the ICA.

Clopidogrel $(300 \mathrm{mg}$ preoperative loading dose, then $75 \mathrm{mg} /$ day) was given for at least 4 weeks to patients who underwent primary stenting. Aspirin (orally $100 \mathrm{mg} /$ day) was given to each patient indefinitely.

\section{Analysis of Blood Samples}

Blood samples were obtained from the radial artery in the cardiac catheterization room before the coronary angiographic study. WBC count, biochemical parameters, and electrolytes were determined by standard laboratory methods.

The hs-CRP was measured by immunonephelometry using the $\mathrm{BN}^{\mathrm{TM}}$ system (Dade Behring Inc Newark, DE, USA). The lower detection limit is $<0.15 \mathrm{mg} / \mathrm{L}$. The intraindividual variability of serum hs-CRP levels was assessed 

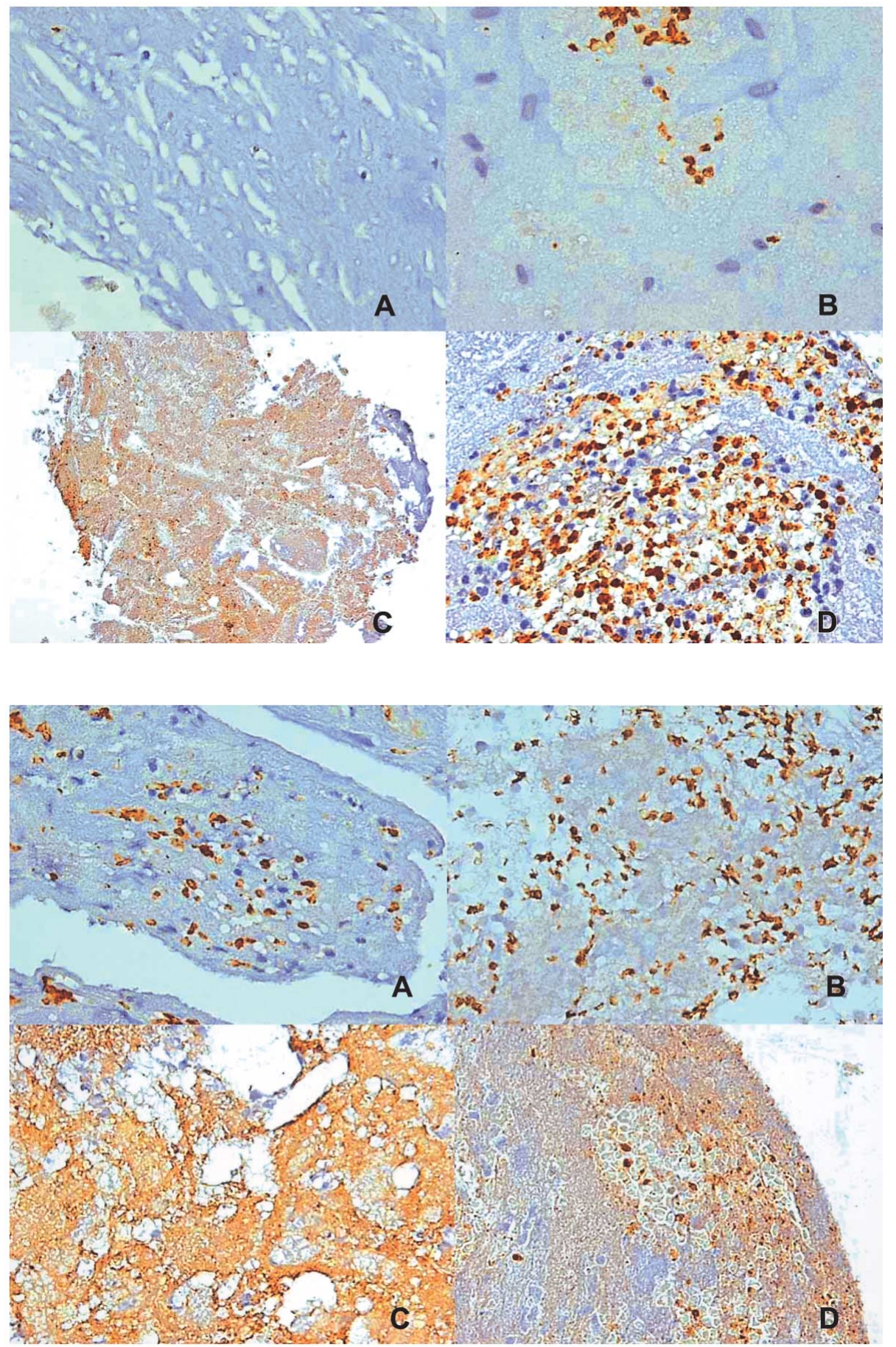

Fig 2. Immunolocalization and staining intensity of C-reactive protein (CRP) in atherothrombotic tissue section $(\times 132)$. Brown-dark color indicates grade zero $(A)$, grade $1+(B)$, grade $2+(C)$, and grade $3+(D)$ of CRP staining within both macrophages and extracellular tissue. Cholesterol clefts were also noted in B and C.
Fig 3. Immunolocalization and staining intensity of $\mathrm{C}$-reactive protein (CRP) in atherothrombotic tissue section $(\times 132)$. (Upper panel) Grade $3+$ of CRP staining within macrophages $(\mathrm{A}, \mathrm{B})$ and grade zero $(\mathrm{A})$ and grade $1+$ (B) of CRP staining within extracellular tissue. (Lower panel) Grade 3+ of CRP staining within extracellular tissue (C,D) and grade zero (C) and grade 1+ (D) of CRP staining within macrophages. in both study patients and at-risk control subjects whose mean intra-assay coefficients of variance were $2.89 \%$ and $2.74 \%$, respectively.

The concentration of sP-selectin was measured using a standard enzyme-linked immunosorbent assay and a commercially available kit ( $\mathrm{R}$ and D Systems; Minneapolis, MN, USA). The assay was sufficiently sensitive to detect concentrations of less than $0.5 \mathrm{ng} / \mathrm{ml}$, according to the manufacturer's instructions. Intra-individual variability of the sP-selectin levels was assessed in both study patients and at-risk control subjects whose mean intra-assay coefficients of variance were $4.78 \%$ and $4.33 \%$, respectively.

\section{Specimen Preparation}

The aspirated tissue was placed in $10 \%$ buffered formalin for IHCS of CRP and macrophage identification. In each case, the gross dimensions of the atherothrombus were measured in centimeters. The atherothrombi were then paraffinized and the paraffin blocks were serially sectioned at $2 \mu \mathrm{m}$ thickness for IHCS in each case.

\section{Immunohistochemical Stains}

Two sections were prepared and incubated with the specific anti-CD68 (Dako Corporation) antibody (at a dilution of 1:50) for the identification of macrophages in each case. Three sections were prepared in each case and IHCS 
Table 1 Baseline Characteristics of Study Patients and At-Risk Control Group

\begin{tabular}{|c|c|c|c|}
\hline & $\begin{array}{c}\text { Study patients } \\
(n=49)\end{array}$ & $\begin{array}{l}\text { At-risk control group } \\
\qquad(n=45)\end{array}$ & $p$ value \\
\hline Age (years) & $61.4 \pm 10.7$ & $60.3 \pm 11.2$ & 0.575 \\
\hline Male gender & $81.6 \%(40)$ & $77.8 \%(35)$ & 0.642 \\
\hline Hypertension & $53.1 \%(26)$ & $48.9 \%(22)$ & 0.686 \\
\hline Current smoker & $49.0 \%(24)$ & $51.1 \%(23)$ & 0.836 \\
\hline Body mass index $\left(\mathrm{kg} / \mathrm{m}^{2}\right)^{*}$ & $26.1 \pm 4.7$ & $25.9 \pm 4.4$ & 0.497 \\
\hline Total cholesterol $(\mathrm{mg} / \mathrm{dl})$ & $215.6 \pm 43.8$ & $214.8 \pm 42.8$ & 0.471 \\
\hline HDL cholesterol $(\mathrm{mg} / \mathrm{dl})$ & $46.4 \pm 14.3$ & $46.9 \pm 14.8$ & 0.712 \\
\hline LDL cholesterol (mg/dl) & $135.2 \pm 36.3$ & $135.4 \pm 37.1$ & 0.543 \\
\hline Triglyceride $(\mathrm{mg} / \mathrm{dl})$ & $145.4 \pm 91.6$ & $126.2 \pm 71.7$ & 0.242 \\
\hline Diabetes mellitus & $28.6 \%(14)$ & $31.1 \%(14)$ & 0.788 \\
\hline WBC count $\left(\times 10^{3} / \mathrm{ml}\right)$ & $10.8 \pm 5.6$ & $6.5 \pm 4.1$ & $<0.0001$ \\
\hline Soluble P-selectin $(\mathrm{ng} / \mathrm{ml})$ & $64.7 \pm 18.1$ & $33.7 \pm 15.6$ & $<0.0001$ \\
\hline$h s-C R P(m g / L)$ & $3.82 \pm 3.07$ & $1.67 \pm 0.89$ & $<0.0001$ \\
\hline Creatinine $(\mathrm{mg} / \mathrm{dl})$ & $1.19 \pm 0.21$ & $1.16 \pm 0.19$ & 0.661 \\
\hline \multicolumn{4}{|l|}{ Medications } \\
\hline Aspirin & $100 \%(49)$ & $100 \%(45)$ & - \\
\hline Clopidogrel & $100 \%(49)$ & $100 \%(45)$ & _- \\
\hline Statins & $63.3 \%(31)$ & $57.8 \%(26)$ & 0.586 \\
\hline ACE inhibitors & $83.7 \%(41)$ & $77.8 \%(35)$ & 0.468 \\
\hline Multivessel disease $e^{\dagger}$ & $51.0 \%(25)$ & $48.9 \%(22)$ & 0.836 \\
\hline PCI to $L A D$ & $42.8 \%(21)$ & $51.1 \%(23)$ & 0.423 \\
\hline$P C I$ to non- $L A D$ & $57.2 \%(28)$ & $48.9 \%(22)$ & 0.423 \\
\hline TIMI-3 flow & $98.0 \%(48)$ & - & - \\
\hline Peak level of $C K-M B(U / L)$ & $698 \pm 778$ & - & - \\
\hline $\operatorname{LVEF}(\%)$ & $53 \pm 11.8$ & - & - \\
\hline 30-day mortality & $2.0 \%(1)$ & - & - \\
\hline
\end{tabular}

Data are mean value $\pm S D$ or $\%$ (number) of patients.

$A C E$, angiotensin-converting enzyme; HDL, high-density lipoprotein; $L D L$, low-density lipoprotein; WBC, white blood cell; hs-CRP, high-sensitivity C-reactive protein; PCI, percutaneous coronary intervention; LAD, left anterior descending artery; TIMI, Thrombolysis in Myocardial Infarction; $C K$, creatine kinase; LVEF, left ventricular ejection fraction.

*Body mass index was defined as weight in kilograms divided by square of the height in meters $\left(\mathrm{kg} / \mathrm{m}^{2}\right)$.

${ }^{\dagger}$ Multivessel disease was defined by stenoses of $>50 \%$ in $\geq 2$ major epicardial coronary arteries.

TIMI-3 flow indicated successful reperfusion.

was carried out using standard avidin-biotin techniques with a commercially available antiserum for CRP (Sigma, St Louis, MO, USA) at a dilution of 1:200. The super sensitive polymer-HRP IHC was used as a detection system (BioGenex). Deparaffinized sections were incubated in $1 \mathrm{mmol} / \mathrm{L}$ EDTA buffer with steam heat before staining for antigen retrieval.

\section{Qualitative Analysis for Staining}

Grading of the staining intensity of CRP was assessed in both macrophages and atherothrombotic tissue (extracellular staining) (Figs 2,3). A qualitative score of $0-3$ was given to each case: 0 indicated no staining; $1+$ indicated $<30 \%$ macrophages staining or $<30 \%$ extracellular staining; $2+$ indicated $30-60 \%$ macrophages staining or $30-60 \%$ extracellular staining; $3+$ indicated $>60 \%$ macrophages staining or $>60 \%$ extracellular staining. The staining was analyzed by a pathologist who was unaware of the procedure and the patients' clinical information.

\section{Statistical Analysis}

Categorical variables were compared using the chisquare test or Fisher's exact test. Continuous variables were compared using the t-test. Log-transformation of hs-CRP and SP-selectin was used to improve the normality for statistical analysis. Continuous variables of hs-CRP among the 3 different grades of staining of CRP were compared using repeated measures ANOVA, and Scheffe's multiple comparison procedure was used for further comparing the significant difference among the 3 groups. SAS statistical software for Windows version 8.2 (SAS Institute, Cary, NC, USA) was used for statistical analysis. A probability value $<0.05$ was considered statistically significant.

\section{Results}

Baseline Characteristics of the Study Patients and At-Risk Control Subjects (Table 1)

The 2 groups did not differ significantly with regard to age, gender, risk factors for coronary artery disease, body mass index, creatinine level, medications, multivessel disease, and incidence of PCI to the left anterior descending coronary artery (LAD) and non-LAD. However, circulating levels of hs-CRP and sP-selectin, and the WBC counts were significantly higher in the study patients than in the at-risk control subjects. The procedural success rate was $98.0 \%$. One patient died in hospital. Thus, the 30-day morality was $2.0 \%$.

\section{Comparison of the Levels of Inflammatory Biomarkers Between the Systemic Circulation and ICA in 49 AMI Patients (Table 2)}

Serum levels of hs-CRP did not differ between the ICA and systemic circulation in the study patients, but the sPselctin level and WBC count were significantly higher in the ICA than in the systemic circulation.

\section{IHCS}

Table 3 shows the different CRP staining intensities of the macrophages and atherothrombotic tissue, as well as 
Table 2 Comparison of the Levels of Inflammatory Biomarkers in the Systemic Circulation and ICA in 49 AMI Patients

\begin{tabular}{lclc}
\hline \hline & ICA & $\begin{array}{c}\text { Systemic } \\
\text { circulation }\end{array}$ & p value \\
\hline$W B C$ count $\left(\times 10^{3} / \mathrm{ml}\right)$ & $14.4 \pm 8.1$ & $10.2 \pm 3.6$ & $<0.0001$ \\
hs-CRP $(\mathrm{mg} / \mathrm{L})$ & $3.427 \pm 2.91$ & $3.82 \pm 3.07$ & 0.337 \\
Soluble P-selectin $(\mathrm{ng} / \mathrm{ml})$ & $80.27 \pm 18.59$ & $64.7 \pm 18.12$ & $<0.0001$ \\
\hline
\end{tabular}

Data are mean value $\pm S D$.

ICA, infarct-related coronary artery; AMI, acute myocardial infarction; $W B C$, white blood cell; $h$ s-CRP, high-sensitivity $C$-reactive protein.

their relationship to the circulating levels of hs-CRP.

The circulating level of hs-CRP was significantly higher in grade $3+$ than in grade $2+$ and grade $\leq 1+(\mathrm{p}<0.0001)$, and in grade $2+$ than in grade $\leq 1+(\mathrm{p}<0.001)$ in macrophage staining of CRP. Additionally, the circulating level of hsCRP was significantly higher in grade $3+$ than in grade $2+$ and grade $\leq 1+(\mathrm{p}<0.0001)$ and in grade $2+$ than in grade $\leq 1+$ in extracellular staining of CRP $(p<0.001)$. Multiple stepwise logistic regression analysis of the variables in Table 1 demonstrated that an increased circulating level of hs-CRP was the only independent predictor of $\geq 2+$ within macrophages (odds ratio $(\mathrm{OR})=3.71,95 \%$ confidence interval $(C I)=2.57-18.54, p<0.0001)$ and of $\geq 2+$ in extracellular tissue $(\mathrm{OR}=7.31,95 \% \mathrm{CI}=4.32-33.2, \mathrm{p}<0.0001)$ staining of CRP.

\section{Impact of Inflammatory Mediators in the ICA on Thrombus Burden}

Pieces of atherothrombi aspirated from the ICA during PCI were measured across all 3 dimensions and then summed into a total volume (width $\times$ height $\times$ length $\mathrm{cm}^{3}$ ). The measurement results demonstrated that $69.4 \%$ of patients (group 1, $\mathrm{n}=34$ ) had a total atherothrombus volume $\geq 0.5 \mathrm{~cm}^{3}$, whereas the other $30.6 \%$ (group 2, $\mathrm{n}=15$ ) had a volume $<0.5 \mathrm{~cm}^{3}$. The mean atherothrombus volume was significantly higher in group 1 than in group $2(0.88 \pm$ $0.24 \mathrm{~cm}^{3}$ vs $\left.0.32 \pm 0.18 \mathrm{~cm}^{3}, \mathrm{p}<0.0001\right)$. Furthermore, the ICA level of sP-selectin were noticeably higher in group 1 than in group 2 patients $(85.67 \pm 16.82$ vs $67.94 \pm 18.54$, $\mathrm{p}<0.0001)$. Moreover, there was a significant correlation between the thrombus volume and the ICA sP-selectin level $(\mathrm{r}=0.414, \mathrm{p}<0.0001)$.
Table 3 Association Between Circulating Level of hs-CRP and Staining Intensity of CRP Within Macrophages and Atherothrombotic Tissue

\begin{tabular}{ccc}
\hline \hline & $\begin{array}{c}\% \\
\text { (no. of patients) }\end{array}$ & $\begin{array}{c}\text { Circulating } h s-C R P \text { level } \\
(\mathrm{mg} / \mathrm{L})\end{array}$ \\
\hline $\begin{array}{c}\text { Macrophage staining } \\
\text { Grade 3+ }\end{array}$ & $32.7 \%(16)$ & $3.61 \pm 2.98^{*}$ \\
Grade 2+ & $18.4 \%(9)$ & $2.81 \pm 2.56^{\dagger}$ \\
Grade $\leq 1$ & $49.0 \%(24)$ & $1.92 \pm 1.18^{\ddagger}$ \\
Extracellular staining & & \\
Grade 3+ & $53.1 \%(26)$ & $3.82 \pm 2.71^{\S}$ \\
Grade 2+ & $16.3 \%(8)$ & $2.91 \pm 1.89^{\| 1}$ \\
Grade $\leq 1$ & $30.6 \%(15)$ & $1.79 \pm 1.09^{\mathscr{I}}$ \\
\hline
\end{tabular}

Data are mean $\pm S D$ of patients.

Abbreviation see in Table 1.

Symbols $(*,+, \ddagger, \S, ", \mathbb{I})$ indicate significant difference (at 0.05 level) by Scheffe's multiple comparison procedure.

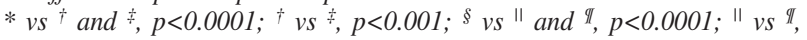
$p<0.001$.

\section{Correlation Between ICA Levels of hs-CPR and WBC Count}

Correlation analysis demonstrated that the increase in the ICA level of sP-selectin was significantly related to the increase in the ICA WBC count $(\mathrm{r}=0.548, \mathrm{p}<0.0001)$ (Fig 4).

\section{Discussion}

This study is original and has several notable findings. First, both the sP-selectin level and WBC count were significantly higher in the ICA than in the systemic circulation in patients with AMI $<6 \mathrm{~h}$ duration undergoing primary PCI. Second, the ICA level of sP-selectin was substantially higher in patients with a large atherothrobotic burden $\left(\geq 0.5 \mathrm{~cm}^{3}\right)$ than in patients with a small atherothrombotic burden $\left(<0.5 \mathrm{~cm}^{3}\right)$. Third, an increased circulating level of hs-CRP was the only independent predictor of increased macrophage and extracellular staining intensity of CRP. Finally, an increased ICA level of sP-selectin was significantly and directly related to an increased WBC count in the ICA.

Accumulating evidence from clinical observations indicates that the CRP level is one of the most powerful predictors of atherosclerosis and vascular death, ${ }^{25,26}$ with a prognostic value exceeding that of low-density lipoprotein cholesterol27 Other clinical observational studies have shown that CRP is related to adverse outcomes in patients

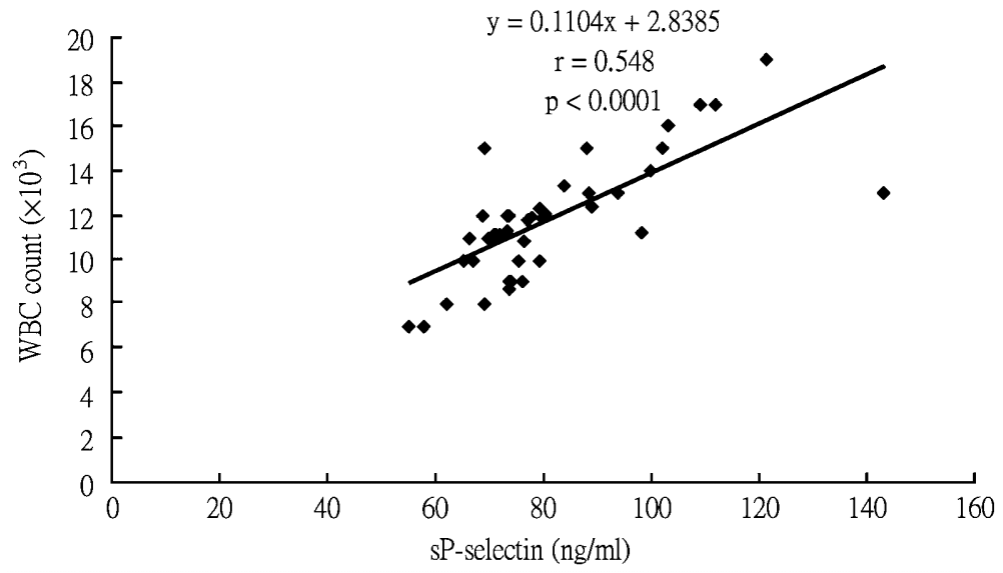

Fig 4. Correlation between infarct intra-coronary artery levels of soluble P-selectin (sP-selectin) and white blood cell counts in patients with acute myocardial infarction onset $<6 \mathrm{~h}$. WBC, white blood cell. 
with acute coronary syndromes 26,28 However, little is known about the localization of CRP in the ICA of survivors of an AMI $<6 \mathrm{~h}$ duration who are undergoing primary PCI. The first important finding of this study was that CRP was stained in the macrophages found in the ICA and in the atherothrombotic tissue aspirated from the ICA. This study thus provides direct evidence of CRP colocalizing with thrombosed coronary atherosclerotic plaque. Previous studies have demonstrated that the direct proatherogenic effects of CRP extend beyond the endothelium to the vascular smooth muscle, ${ }^{12}$ and other in vitro studies have demonstrated that CRP directly participates in the initiation and propagation of atherosclerosis!11,29 The findings of the present ex vivo study are essential information supporting the findings of those previous in vitro studies.11,12,29

The second important finding of this study was that the circulating level of hs-CRP was strongly and independently correlated with increased intensity of both macrophage and extracellular tissue staining of CRP. Previous studies ${ }^{30,31}$ have shown that the circulating concentration of human CRP, the classical acute phase protein, is always increased following AMI, starting approximately $6 \mathrm{~h}$ after onset of symptoms and peaking after about $50 \mathrm{~h}{ }^{32-34}$ Therefore, according to those studies, ${ }^{32-35}$ the serum level of hs-CRP can be classified into 2 different intervals in the clinical setting of $\mathrm{AMI}^{4}$ (ie, $6 \mathrm{~h}$ before and after the onset of symptoms). Patients enrolled in the present study, who experienced AMI with duration $<6 \mathrm{~h}$ undergoing primary PCI, showed no difference in the serum hs-CRP level in the ICA and in the systemic circulation. This finding suggests that circulating level of hs-CRP within $6 \mathrm{~h}$ of onset of AMI, before the participation of myocardial damage in the inflammatory process within the atherosclerotic plaque, reflected the baseline level of serum hs-CRP in the present patients. Moreover, the serum level of hs-CRP was significantly higher among the study patients than the at-risk control subjects. Therefore, we suggest that an elevated serum hsCRP level prior to AMI portends rupture of vulnerable plaque. This suggestion, based on clinical observation and laboratory findings, is further supported by a recent autopsy study that demonstrated that an increased serum level of hs-CRP is strongly related to atherothrombi and plaque burden in patients with severe coronary artery disease who died suddenly?

Although animal and in vitro studies have stressed the important role of P-selctin in facilitating atherosclerosis lesion development ${ }^{36}$ mediating endothelial-leukocyteplatelet interactions, ${ }^{16-19}$ and stabilizing platelet aggregation, ${ }^{21}$ data on the role and circulating level of sP-selectin following AMI remains limited37,38 Additionally, no data are available on the level of sP-selectin in the ICA of patients following AMI. The third important finding of this study was that among the study patients the serum level of sP-selectin was markedly higher in the ICA than in the systemic circulation. Furthermore, an increased ICA sPselctin level was significantly associated with increased atherothrombotic burden in the ICA. Thus, we suggest that sP-selectin may play a crucial role in thrombus formation and organized-thrombus maintenance in the ICA. This suggestion is supported by a previous experimental study demonstrating that $\mathrm{sP}$-selectin facilitates fibrin deposition within the thrombus ${ }^{20}$

The reasons for the elevated $\mathrm{sP}$-selectin level in the ICA compared with that in systemic circulation in the present study remains uncertain. However, we hypothesize that
P-selectin is rapidly expressed on the surface of activated platelets and endothelial cells after plaque rupture and thrombus formation in the coronary artery! ${ }^{17}$ Additionally, compared with the systemic circulation, the ICA should display a more rigorous response in both the expression and enzymatic cleavage of sP-selectin, resulting primarily from the twin stimulations of endothelial-platelet-leukocyte interaction and thrombus formation. Furthermore, most $\mathrm{P}$-selectin is retrieved and accumulates in the occluded ICA after being cleaved into the soluble form (sP-selectin) rather then being released into the circulation. Previous studies have demonstrated that glycoprotein P-selectin, a membrane component of cell storage granules, ${ }^{39}$ is rapidly translocated from the a-granules of platelets and the Weibel-Palade bodies of endothelial cells to the cell surface following an inflammatory process or other stimulation.16,40 Consequently, both enzymatic cleavage of expressed Pselectin and alternative splicing of P-selectin messenger ribonucleic acid occur quickly, giving rise to sP-selectin detectable in the peripheral blood.1-43 Thus, our suggestions, based on laboratory findings, are further supported by these previous studies ( $^{3-43}$

Recent studies have demonstrated that an increased WBC count in patients with AMI is strongly associated with reduced epicardial blood flow and myocardial reperfusion, thromboresistance, and adverse clinical outcomes?22,23 The present study showed a substantially increased WBC count in study patients compared with at-risk control subjects. Importantly, the WBC count was significantly higher in the ICA than in the systemic circulation. Furthermore, a linear correlation was found between WBC count and sPselectin level in the ICA. We suggest that an increased ICA level of sP-selctin reflects the recruitment and sequestration of WBC in the ICA following AMI. Furthermore, we also suggest that sequestration of $\mathrm{WBC}$ and $\mathrm{sP}$-selectin in the ICA played a key role in thrombus formation in the study patients. The suggestions presented here based on clinical observation and laboratory findings are supported by previous studies that demonstrated that leukocyte accumulation promoting fibrin deposition is mediated in vivo by $\mathrm{P}$ selectin on adherent platelets ${ }^{20}$ Accordingly, the findings of this study reinforce the recent reports of elevated WBC count being associated with thromboresistance and reduced myocardial reperfusion.22

\section{Study Limitations}

First, the PercuSurge device was not used in the at-risk control subjects. Therefore, this investigation could not provide information regarding the ICA levels of hs-CRP, sP-selectin and WBC count of these subjects. Second, the staining intensity of CRP within macrophages in systemic circulation was not performed. Hence, this investigation could not provide information regarding the difference in staining intensity of CRP within macrophages in the ICA and systemic circulation in the study patients. Finally, without an intravascular ultrasound study, we could not provide a correlation between atherothrombus volume and plaque burden. Autopsy studies previously demonstrated that moderate plaque burden was usually found in most infarct-related arteries. ${ }^{4-45}$ Thus, atherothrombus volume may not have an association with plaque burden.

\section{Conclusion}

The present study demonstrated that the circulating level 
of hs-CRP was independently associated with the staining intensity of CRP in the ICA. This finding highlights the possible role of CRP in contributing to the rupture of atherosclerotic plaque. Moreover, this study revealed the sequestration of sP-selectin and WBC in the ICA, indicating that these inflammatory mediators could, at least in part, participate in thrombus formation and stabilization following AMI.

\section{Acknowledgements}

We would like to thank Ms. Fang-Yu Tai for her technical assistance. This study was supported by a program grant from Chang Gung Memorial Hospital, Chang Gung University (Grant no. CMRPG 83004).

\section{References}

1. Ross R. The pathogenesis of atherosclerosis: A prospective for the 1990s. Nature 1993; 362: 802-809.

2. Van der Wall AC, Becker AE, van der Loos CM, Das PK. Site of intimal rupture or erosion of thrombosed coronary atherosclerotic plaques is characterized by an inflammatory process irrespective of the dominant plaque morphology. Circulation 1994; 89: 36-44.

3. Ross R. Atherosclerosis: An inflammatory disease. $N$ Engl J Med 1999; 340: $115-126$.

4. Yip HK, Wu CJ, Chang HW, Yang $\mathrm{CH}$, Yeh $\mathrm{KH}$, Chau S, et al. Levels and values of serum high-sensitivity C-reactive protein within 6 hours after the onset of acute myocardial infarction. Chest 2004; 126: $1417-1422$

5. Yip HK, Wu CJ, Yang CH, Chang HW, Fang CY, Hung WC, et al. Serial changes in circulating concentrations of soluble CD40 ligand and $\mathrm{C}$-reactive protein in patients with unstable angina undergoing coronary stenting: Role of inflammatory mediators in predicting late restenosis. Circ J 2005; 69: 890-895.

6. Yip HK, Hung WC, Yang CH, Chen YH, Cheng CI, Chen SM, et al. Serum concentrations of high-sensitivity C-reactive protein predict progressively obstructive lesions rather than late restenosis in patients with unstable angina undergoing coronary artery stenting. Circ $J$ 2005; 69: $1202-1207$.

7. Burke AP, Farb A, Malcom GT, Liang YH, Smialek J, Virmani R. Coronary risk factors and plaque morphology in men with coronary disease who died suddenly. N Engl J Med 1997; 336: 1276-1282.

8. Mulvihill NT, Foley JB. Inflammation in acute coronary syndromes. Heart 2002; 87: 201-204.

9. Burke AP, Tracy RP, Kologie F, Malcom GT, Zieske A, Butys R, et al. Elevated C-reactive protein values and atherosclerosis in sudden coronary death: Association with different pathologies. Circulation 2002; 105: 2019-2023.

10. Hansson GK. Immune and inflammatory mechanisms in the development of atherosclerosis. Br Heart J 1993; 69: S38-S42.

11. Pasceri V, Willerson JT, Yeh ET. Direct proinflammatory effect of C-reactive protein on human endothelial cells. Circulation 2000; 102: $2165-2168$.

12. Verma S, Li SH, Badiwala MV, Weisel RD, Fedak PWM, Li RK, et al. Endothelin antagonism and interleukin-6 inhibition attenuate the proatherogenic effects of C-reactive protein. Circulation 2002; 105: $1890-1896$

13. Koenig W, Sund M, Frohlich M, Fischer HG, Lowel H, Doring A, et al. C-reactive protein, a sensitive marker of inflammation, predicts future risk of coronary heart disease in initially healthy middle-aged men: Results from the MONICA Augsburg Cohort Study, 1984 to 1992. Circulation 1999; 99: 237-242.

14. Rider PM, Hennekens CH, Buring JE, Rifani N. C-reactive protein and other markers of inflammation in the prediction of cardiovascular disease in women. $N$ Engl J Med 2000; 342: 836-843.

15. Rider PM. High-sensitivity C-reactive protein: Potential adjunct for global risk assessment in primary prevention of cardiovascular disease. Circulation 2001; 103: $1813-1818$.

16. Hsu-Lin SL, Berman CL, Furie BC, August D, Furie B. A platelet membrane protein expressed during platelet activation and secretion: Studies using a monoclonal antibody specific for thrombin-activated platelets. J Biol Chem 1984; 59: 9121-9126.

17. Carlos TM, Harlan JM. Leukocyte-endothelial cell adhesion molecules. Blood 1998; 84: 2069-2101.

18. Frenette PS, Johnson RC, Hynes RO, Wagner DD. Platelets roll on stimulated endothelium in vivo: An interaction mediated by endothelial p-selectin. Proc Natl Acad Sci USA 1995; 92: 7450-7454.

19. Gamble JR, Skinner MP, Berndt MC, Vadas MA. Prevention of activated neutrophil adhesion to endothelium by soluble adhesion protein GMP 140. Science 1990; 249: 414-417.

20. Palabrica T, Lobb R, Furie BC, Aronovitz M, Benjamin C, Hsu YM, et al. Leukocyte accumulation promoting fibrin deposition is mediated in vivo by p-selectin on adherent platelets. Nature 1992; 359: $848-851$.

21. Merten M, Thiagarajan P. P-selectin expression on platelets determines size and stability of platelet aggregates. Circulation 2000; 102: $1931-1936$.

22. Barron HV, Cannon CP, Murphy SA, Braunwald E, Gibson M. Association between white blood cell count, epicardial blood flow, myocardial perfusion, and clinical outcomes in the setting of acute myocardial infarction: A thrombolysis in myocardial infarction 10 substudy. Circulation 2000; 102: 2329-2334.

23. Barron HV, Harr SD, Radfort MJ, Wang Y, Krumholz HM. The association between white blood cell count and acute myocardial infarction mortality in patients $\geq 65$ years of age: Findings from the cooperative cardiovascular project. J Am Coll Cardiol 2001; 38: $1654-1661$.

24. Yip HK, Chen MC, Chang HW, Hang CL, Hsieh YK, Fang CY, et al. Angiographic morphologic features of infarct-related arteries and timely reperfusion in acute myocardial infarction: Predictors of slowflow and no-reflow. Chest 2002; 122: 1322-1332.

25. Shak PK. Circulating markers of inflammation for vascular risk prediction: Are they ready for prime time? Circulation 2000; 101: $1758-1759$.

26. Mueller C, Buettner HJ, Hodgson JM, Marsch S, Perruchoud AP, Roskamm H, et al. Inflammation and long-term mortality after nonST elevation acute coronary syndrome treated with a very early invasive strategy in 1042 consecutive patients. Circulation 2002; 105: $1412-1415$

27. Ridker PM, Rifai N, Rose L, Buring JE, Cook NR. Comparison of Creactive protein and low-density lipoprotein cholesterol levels in the prediction of first cardiovascular events. N Engl J Med 2002; 347: $1557-1565$.

28. Lindahl B, Toss H, Siegbahn A, Venge P, Wallentin L. Markers of myocardial damage and inflammation in relation to long-term mortality in unstable coronary artery disease. $N$ Engl J Med 2000; 343: $1139-1147$.

29. Pasceri V, Chang J, Willerson JT, Yeh ETH. Modulation of C-reactive protein-mediated monocyte chemoattractant protein-1 induction in human endothelial cell by anti-atherosclerosis drugs. Circulation 2001; 103: $2531-2534$.

30. Morrone G, Ciliberto G, Oliviero S, Arcone R, Dente L, Content J, et al. Recombinant interleukin 6 regulates the transcriptional activation of a set of human acute phase genes. J Biol Chem 1988; 263: 12554 12558.

31. Le J, Vilcek J. Interleukin 6: A multifunctional cytokine regulating immune reactions and the acute phase protein response. Lab Invest 1989; 61: 588-602.

32. Ablij HC, Meinders AE. C-reactive protein: History and revival. Eur J Intern Med 2002; 13: 412-422.

33. Tomoda H, Aoki N. Prognostic value of C-reactive protein levels within six hours after the onset of acute myocardial infarction. Am Heart J 2000; 140: 324-328.

34. Kushner I, Broder ML, Karp D. Control of the acute phase response: Serum C-reactive protein kinetics after acute myocardial infarction. J Clin Invest 1978; 61: 235-242.

35. deBeer FC, Hind CRK, Fox KM, Allan RM, Maseri A, Pepys MB. Measurement of serum C-reactive protein concentration in myocardial ischemia and infarction. Br Heart J 1982; 47: 239-243.

36. Burger PC, Wagner DD. Platelet P-selectin facilitates atherosclerotic lesion development. Blood 2003; 101: 2661-2666.

37. Shimomura H, Ogawa H, Arai H, Moriyama Y, Takazoe K, Hirai N, et al. Serial changes in plasma levels of soluble p-selectin in patients with acute myocardial infarction. Am J Cardiol 1998; 81: 397-400.

38. Gurbel PA, O'Connor CM, Dalesandro MR, Serebruany VL. Relation of soluble and platelet p-selectin to early outcome in patients with acute myocardial infarction after thrombolytic therapy. Am $J$ Cardiol 2001; 87: 774-777.

39. Berman CL, Yeo EL, Wencel-Drake JD, Furie BC, Grinsberg MH, Furie B. A platelet alpha-granule membrane protein that is associated with the plasma membrane after activation: Characterization and subcellular localization of platelet activation-dependent granule-external membrane protein. J Clin Invest 1986; 78: 130-137.

40. McEver RP, Beckstead JH, Moore KL, Marshall-Carlson L, Bainton DF. GMP-140, a plateleta-granule membrane protein, is also synthesized by vascular endothelial cells and is localized in Weibel-Palade bodies. J Clin Invest 1989; 84: 92-99.

41. Ishiwata N, Takio K, Katayama M, Watanabe K, Titani K. Alterna- 
tive spliced isoform of P-selectin is present in vivo as a soluble molecule. J Biol Chem 1994; 269: 23708-23715.

42. Johnston GI, Bliss GA, Newman PJ, McEver RP. Structure of the human gene encoding granule membrane protein-140, a member of the selectin family of adhesion receptors for leukocytes. J Biol Chem 1990; 265: $21381-21385$.

43. Michelson A, Bernard M, Hechtman H. In vivo trafficking of platelets: Circulating degranulated platelets rapidly loose surface but continue to circulate and function. Proc Natl Acad Sci USA 1996; 93:
$11877-11882$.

44. Davies MJ, Thromas AC. Plaque fissuring: The cause of acute myocardial infarction, sudden death, and crescendo angina. Br Heart $J$ 1985; 53: 363-373.

45. Roberts WC. Qualitative and quantitative comparison of amounts of narrowing by atherosclerotic plaques in the major epicardial coronary arteries at autopsy in sudden coronary death, transmural acute myocardial infarction and unstable angina pectoris. Am J Cardiol 1989; 64: 324-328. 